\title{
Effect of Sex Sorted Semen in Synchronized Estrus on Pregnancy Rate and Female Ratio in Gir Cows
}

\author{
P.M. Shinde, M.V. Ingawale, C.H. Pawshe, S.P. Waghmare, S.W. Hajare, R.S. Ingole
}

10.18805/IJAR.B-4793

\begin{abstract}
Background: At present there is huge demand for Gir cow females however, prolonged inter calving period, more inseminations per conception and post-partum anestrus are the predominant reproductive disorder along with use of unsexed semen limit the birth of more females in Gir cows. The present research study was conducted to study the effect of sex sorted semen in synchronized estrus with Ovsynch protocol on pregnancy rate and gender ratio in Gir cows.

Methods: Total twenty Gir cows that have completed post-partum period of sixty days with normal reproductive genitalia, without clinical as well as subclinical infection were selected and divided into two equal groups. The cows from both the groups were synchronized with Ovsynch protocol. In Group- I $(n=10)$, the cows were inseminated with sex sorted semen while in Group-II, the cows were inseminated with coneventional semen. The pregnancy rate and gender ratio was recorded.

Result: Efficacy of estrus synchronization was 100.00 per cent for Gir cows treated by Ovsynch protocol in both groups. The pregnancy rate was numerically lower after Al with sex sorted semen $(40 \%)$ than conventional semen $(50 \%)$ and results are non significant $(\mathrm{P}<0.05)$ with $100 \%$ calving rate. The proportion of female calves born from sex sorted semen $\mathrm{Al}$ was $75 \%$ and from conventional semen was $60 \%$. The proportion of live calves born from sex sorted and conventional semen Al was $100 \%$. The sex sorted semen may be used in Ovsynch protocol in Gir cows.
\end{abstract}

Key words: Gir, Estrus, Ovsynch, Sex sorted semen, Syncronization.

\section{INTRODUCTION}

Gir cow is considered as the best breed due to its superior qualities and best milker among Indigenous cattle. In India presently, Indigenous cow's ghee and urine is considered useful for making medicines based on Panchgavya and used as a best mixture in Ayurved (Parkavi et al., 2021). Its milk is of premium quality milk due to the presence of A-2 beta casein and has more demand in urban educated pepoles. The average milk yield of Gir cows is 1930 litres in 300 days, average age at first heat and calving were 1149 and 1534 day, respectively while average dry period and inter-calving period were 123 and 423 days, respectively. At present there is huge demand for Gir cow females in India however, prolonged inter calving period, more inseminations per conception and post-partum anestrus are the predominant reproductive disorder that limit the birth of more females in cows.

Reduced reproductive efficiency leading to prolonged inter calving period is one of the most important causes of economic losses in livestock (Sewalem et al., 2008). For archiving maximum reproductive efficiency, each cow must be reproduced as frequently as possible and maintain a standard inter-calving period of 12 months. Various management strategies and estrus synchronization protocols are implemented to induce estrus and ovulations in cows. Ovsynch is one of the estrus synchronization protocols consisting of two injections of gonadotropic releasing hormone $(\mathrm{GnRH})$ combined with single administration of prostaglandin $\mathrm{F}_{2} \alpha\left(\mathrm{PGF}_{2} \alpha\right)$ and used in cyclic animals for synchronization of ovulation and fixed time artificial insemination (Singh, 2014). The main advantage
Department of Animal Reproduction, Gynaecology and Obstetrics, Post Graduate Institute of Veterinary and Animal Sciences, Akola444 104, Maharashtra, India.

Corresponding Author: M.V. Ingawale, Department of Animal Reproduction, Gynaecology and Obstetrics, Post Graduate Institute of Veterinary and Animal Sciences, Akola-444 104, Maharashtra, India. Email: drmvingawale@rediffmail.com

How to cite this article: Shinde, P.M., Ingawale, M.V., Pawshe, C.H., Waghmare, S.P., Hajare, S.W. and Ingole, R.S. (2022). Effect of Sex Sorted Semen in Synchronized Estrus on Pregnancy Rate and Female Ratio in Gir Cows. Indian Journal of Animal Research. DOI: $10.18805 /$ IJAR.B-4793.

Submitted: 30-09-2021 Accepted: 23-12-2021 Online: 14-01-2022

of Ovsynch protocol is estrus synchronization can be done at all the stages of estrus cycle and synchronization of estrus as well ovulation which occur are very effective for improving reproductive performance (Paul and Praksh, 2005).

The predetermining of sex has valuable impact on livestock industry because of its economic gains with objective to obtain a calf of a particular sex. Use of sorted semen decouples the number of replacement of heifers required for milk production and increases the rate of genetic progress. Sexed semen is generally accessible now however, the main factors in the degree of utilization of sex sorted semen are pregnancy rate, per cent of female calves born and cost of calf production.

The growing demands for Gir females can be achieved by application of sex sorted semen in spontaneous estrus as well as in synchronized estrus. Considering the above 
paucity and meager research on use of sex sorted semen in estrus synchronized Gir cows in India, the present research work was conducted to study the pregnancy rate and female ratio of sexed semen in estrus synchronized Gir cows with Ovsynch protocol.

\section{MATERIALS AND METHODS}

The present research work was carried on twenty lactating multiparous Gir cows from Adarsh Gorakshan farm Mhaispur, at farmer's doorstep in nearby villages in Akola and at Department of Animal Reproduction, Post Graduate Institute of Veterinary and Animal Sciences, Akola.

The average age was 5.9 years, average milk yield was 6.4 litters per day and average parity was 3.2 in selected cows. The vaccination and deworming status, any reproductive abnormalities and last date of parturition were recorded. The Gir cows that have completed post-partum period of sixty days with normal reproductive genitalia, without clinical as well as subclinical infection were selected randomly. All cows were housed in shed with clean dry flooring system. The cows were sent in open for grazing from 10 am to $3 \mathrm{pm}$ and provided compounded concentrate according to milk yield. All cows were provided with fresh drinking water twice daily.

The selected Gir cows were examined gynaecoclinically and cows with palpable ovarian structure like follicle and corpus luteum were divided irrespective of age, milk production and parity. All the selected multiparous Gir cows were dewormed using injection Ivermectin @ $1 \mathrm{ml}$ per 50 $\mathrm{kg}$ body weight subcutaneously, initial treatment with injection vitamin $A D_{3} E$ and $H, 5 \mathrm{ml} \mathrm{l} / \mathrm{M}$ and supplemented with chelated mineral mixture $(1 \mathrm{~kg}) 50 \mathrm{gm}$ daily orally after first gynaecological examination. These randomly selected cows were divided into two groups $(n=10)$.

\section{Group- I (Ovsynch with sex sorted semen)}

One week after presynchronization treatment, cows from this group were treated with Ovsynch protocol with Inj. Buserlin acetate $10 \mu \mathrm{g}$ on day first Inj. Cloprostenol Sodium $500 \mu \mathrm{g}$ on day 7 and Inj. Buserlin acetate $10 \mu \mathrm{g} \mathrm{i} / \mathrm{m}$ on day 9 and inseminated with sex sorted Gir bull semen.

\section{Group- II (Ovsynch with conventional semen)}

One week pre synchronization treatment, cows from this group were treated with Ovsynch protocol with Inj. Buserlin acetate $10 \mu \mathrm{g}$ on day first Inj. Cloprostenol Sodium $500 \mu \mathrm{g}$ on day 7 and Inj. Buserlin acetate $10 \mu \mathrm{g} \mathrm{i/m}$ on day 9 and inseminated with conventional Gir bull semen.

The cows were observed for estrus exhibition after the injection of $\mathrm{PGF}_{2} \alpha(\mathrm{d} 7)$ and different estrus symptoms like congestion of vaginal mucus membrane, vaginal discharge and tumification of vulva were noted by visual observations in the morning and evening. Gir bull conventional and sex sorted semen straws were purchased from Bhartiya Agro Industries Foundation (BAIF) Development Research Foundation, Uruli Kanchan, Pune (M.S.) India which were stored in Liquid Nitrogen $\left(\mathrm{LN}_{2}\right)$. In both the group, inseminations were carried out after 1620 hrs of last $\mathrm{GnRH}$ injection. The pregnancy diagnoses were carried out by per rectal $(P / R)$ examination in inseminated buffaloes after two months. The pregnancy rate of sex sorted semen and conventional semen groups were analyzed by Chi-sequare test by using software WASP of ICAR, Goa.

\section{RESULTS AND DISCUSSION}

\section{Efficacy of Ovsynch protocol in Gir cows}

Efficacy of estrus synchronization was recorded to be 100.00 per cent in present study for Gir cows treated with Ovsynch protocol in both groups (Table 1). The Gir cows showed better treatment response for Ovsynch protocol. These findings are in harmony with earlier results reported by Ammu et al. (2012) in anestrus Gir cows, Dhami et al. (2015) in

Table 1: Relative efficacy of Ovsynch protocol on pregnancy rate and distribution of gender after Al with sex sorted and conventional semen in Gir cows.

\begin{tabular}{|c|c|c|}
\hline Particulars & $\begin{array}{c}\text { Group-I } \\
\text { Sex sorted semen }\end{array}$ & $\begin{array}{c}\text { Group-II } \\
\text { Conventional semen }\end{array}$ \\
\hline \multicolumn{3}{|l|}{ Efficacy of Ovsynch syncronization protocol } \\
\hline No. of cows synchronized with Ovsynch protocol & 10 & 10 \\
\hline No. of cows exhibited oestrus & 100 & 100 \\
\hline \multicolumn{3}{|l|}{ Pregnancy rate } \\
\hline No. of cows insmeinated & 10 & 10 \\
\hline No. of Gir cows became pregnant & 4 & 5 \\
\hline Pregnancy rate $(\%)$ & 40 & 50 \\
\hline \multicolumn{3}{|l|}{ Calving rate } \\
\hline No. of cows calved & 4 & 5 \\
\hline$\%$ calved & 100 & 100 \\
\hline \multicolumn{3}{|l|}{ Gender of calves } \\
\hline No. of calves & 4 & 5 \\
\hline No. of female calves & 3 & 3 \\
\hline$\%$ female calves & 75 & 60 \\
\hline
\end{tabular}


cross bred anoestrus cows, Barolia et al. (2016) in repeat breeding Gir cows.

\section{Estrus signs in Ovsynch protocol in Gir cows}

Estrus signs such as tumification of vulvar lips, vaginal discharge and congestion of vaginal mucus membrane were recorded in the Ovsynch synchronized Gir cows. The tummification of vulval lips symptom was shown by 60 percent (6/10) cows and 50 per cent (5/10) cows in Group I and II, respectively. Congestion of vaginal mucus membrane shown by 70 per cent $(7 / 10)$ cows and the signs of vaginal discharge was shown by $60(6 / 10)$ per cent cows in both the groups. Congestion of vaginal mucus membrane sign was predominantly shown by Gir cows in Ovsynch synchronized estrus.

The findings observed in the present research are not in harmony with Stevenson et al. (1996) reported signs of nervousness, mucous discharge and occasional mounting activity in only 3 of 85 cows (3.5 per cent) in Ovsynch protocol in buffaloes. Kundalkar et al. (2014) reported the estrus signs like congestion of vaginal mucous membrane were exhibited by $87.50(7 / 8)$ per cent, tumification of vulva by $50(4 / 8)$ per cent and vaginal discharge by 37.50 (3/8) per cent by buffaloes synchronized with Ovsynch protocol in buffaloes.

Neglia et al. (2003) that reported 88 per cent of Italian Mediterranean buffaloes had a tonic uterus on the day of $\mathrm{Al}$ which treated with Ovsynch protocol. The variation in the estrual signs shown may be due to variation in species, breed, season, feeding and management, frequency of estrus detection and yield of animals.

\section{Pregnancy rate of sex sorted and conventional semen in Gir cows}

The pregnancy rate was lower after Al with sex sorted semen $(40 \%)$ than conventional semen $(50 \%)$ and results are non significant $(\mathrm{P}<0.05)$. There was no difference between sex sorted and conventional semen for calving rate. The average pregnancy and calving rates for sex sorted semen Als were $40 \%$ and $100 \%$ and for conventional semen Als were $50 \%$ and $100 \%$, respectively. The proportion of female calves born from sex sorted semen $\mathrm{Al}$ was $75 \%$ and from conventional semen was $60 \%$. The proportion of live calves born from sex sorted and conventional semen Al was $100 \%$ (Table 1).

Pregnancy rate for sex sorted semen obtained in present research work was similar to those obtained by Sharma et al. (2018) who observed $40 \%$ pregnancy rate in cows. Joshi et al. (2021) observed the overall conception rate of sex sorted semen was $39.92 \pm 0.5$ per cent which is similar to present research findings.

In concurrence with present research findings, Weigal, (2004) reported higher pregnancy rates for sexed semen in Jersey and Holstein heifer $43 \%$ and $46 \%$ at dose of $1.5 \times 10^{6}$ and $6 \times 10^{6}$ respectively. Presicce et al. (2005) observed $42.8 \%$ at dose of $4 \times 10^{6}$, Borchersen and Peacock, (2009) reported pregnancy rate in Holstein, Jersey and Red breed as $49.3 \%, 46.6 \%$ and $60.2 \%$, respectively. DeJarnette et al. (2010) observed pregnancy rate of $44 \%$ and $46 \%$ at dose of $2.1 \times 10^{6}$ and $3.5 \times 10^{6}$. Lu et al. (2010) recorded $69.7 \%$. DeJarnette et al. (2011) observed $44 \%$ at dose of $10 \times 10^{6}$.Gaviraghi et al.(2013) observed $49.8 \%, 48 \%$ and $47 \%$ at dose of $4 \times 10^{6}, 6 \times 10^{6}$ and $8 \times 10^{6}$, respectively. Kurykin et al. (2016) reported pregnancy rate in induced estrus $\mathrm{Al}$ $(41.7 \%)$ which is lower than spontaneous estrus $\mathrm{Al}(53.4 \%)$.

Lower pregnancy rates in sex sorted semen than the results of present findings were recorded by Doyle et al. (1999) $31.8 \%$ andersson et al. (2004) recorded $21 \%$ at sperm dose of $2 \times 10^{6}$. Weigal (2004) observed $31 \%$ in Jersey cows. Andersson et al. (2006) observed 21\%, Norman et al. (2010) reported 39\%. DeJarnette et al. (2011) observed $38 \%$, Rhinehart et al. (2011) observed 38\% in heifers and $33 \%$ in cows. Gaviraghi et al. (2013) reported $31.2 \%$. Healy et al. (2013) and Mallory et al. (2013) observed 31.6\% and $38 \%$, respectively. Karakaya et al. (2014) recorded pregnancy rate at day 31 and at day 62 as $31.8 \%$ and $25.7 \%$, respectively. Abdalla et al. (2014) recorded $34 \%$ and $32.2 \%$ at day 40 and 90, respectively and Patel and Jethwa (2019) observed $39.53 \%$ pregnancy rate.

Pregnancy rate for conventional semen insemination obtained in present research work was similar to those obtained by Sharma et al. (2018) who recorded $49.32 \%$. In comparison with present research findings, the higher pregnancy rates were recorded for conventional semen by Weigal (2004) reported $62 \%$ at dose of $20 \times 10^{6}$ in New-York, in Jersey $61 \%$ at California. Bodmer et al. (2005) observed $59.3 \%$ at dose of $2 \times 10^{6}$. Borchersen and Peacock (2009) reported pregnancy rate in Holstein, Jersey and Red breed as $61.9 \%, 53.9 \%$ and $65.4 \%$, respectively. DeJarnette et al. (2010) observed $61 \%$ at dose of $15 \times 10^{6}$. Norman et al. (2010) recorded $56 \%$ in heifers. De Jarnette et al. (2011) observed $55 \%$ and $60 \%$ at dose of $2.1 \times 10^{6}$ and $10 \times 10^{6}$ respectively. Gaviraghi et al. (2013) recorded $54.9 \%$ at dose of $2 \times 10^{6}$. Mallory et al. (2013) observed 68\%. Djedovic et al. (2016) recorded 55\%. Abdalla et al. (2014) recorded 62.5\%, 57.8\% at day 40 and day 90 of pregnancy. Dowad and Elbaz (2020) recorded $61.47 \%$ pregnancy rate in heifers.

While lower pregnancy rates in conventional semen than result of present study were recorded by Doyle (1999) $40.9 \%$ andersson et al. (2004) observed $32 \%$ and $46 \%$ at dose of $2 \times 10^{6}$ and $15 \times 10^{6}$, respectively. Anderson et al. (2006) observed 46\%, Healy et al. (2013) and Karakaya et al. (2014) observed $39.6 \%$ and $39 \%$, respectively. The variation in the pregnancy rate may be difference in species, breed, parity, managemental conditions, season, body condition score, exogenous supplementation of hormones and time inseminations.

The proportion of female calves born after application of sex sorted semen recorded in the current study is lower than other earlier reports obtained by Andersson et al., (2006) 82\%, Healy et al. (2013) 86\%, Abdalla et al. (2014) 89.6\%, Lu et al. (2015) 87.6\%, Sharma et al. (2018) $82.14 \%$ and Patel and Jethawa (2019) $86.15 \%$. The female calves born after insemination with conventional semen in current study is higher than the earlier reports by Andersson et al. 
(2006) 49\%, Healy et al. (2013) 48\%, Abdalla et al. (2014) $50 \%$ and Sharma et al. (2018) $50.68 \%$.

\section{CONCLUSION}

The Ovsynch is effective protocol for estrus synchronization and the sex sorted semen may be used in Ovsynch protocol in Gir cows.

\section{REFERENCES}

Abdalla, H., Ali, M.A., El-Tarabany, M.S. (2014). Fertility of commercial sexed semen and the economic analysis of its application in Holstein heifers. Advances in animal and Veterinary Sciences. 2(9): 535-542.

Ammu, Ramakrishnan, Dhami, A.J., Naikoo, M., Parmar. B.C., Divekar, B.S. (2012). Estrus induction and fertility response in post-partum anoestrus Gir cows. Indian J. Anim. Reproduction. 33(1): 37-42.

Anderson, M., Taponen, J., Koskinena, E., Dahlbomb, M.M. (2006). Pregnancy rates in lactating holstein-friesian cows after artificial insemination with sexed sperm. Reproduction in Domestic Animals. 41: 95-97.

Anderson, M., Taponena, J., Koskinena, E., Dahlbomb, M. (2004). Effect of insemination with doses of 2 or 15 million frozenthawed spermatozoa and semen deposition site on pregnancy rate in dairy cows. Theriogenology. 61: 1583-1588.

Barolia, Y., Shende, K., Vaishnava, C.S., Nagda, R.K. (2016). Comparative study of cosynch and ovsynch protocol on fertility in repeat breeder gir cow. International Journal of Science, Environment and Technology. 5(4): 1874 - 1878.

Bodmer, M., Janett, F., Hässig, M., Daas, N.D., Reichert, P., Thun, R. (2005). Fertility in heifers and cows after low dose insemination with sex-sorted and non-sorted sperm under field conditions. Theriogenology. 64: 1647-1655.

Borchersen, S. and Peacock, M. (2009). Danish A.I. field data with sexed semen. Theriogenology. 71: 59-63.

Dawod, A. and Hamed, E. (2020). Effect of sexed semen, puberty and breeding ages on fertility of Holstein dairy heifers treated with double Ovsynch protocol. Tropical Animal Health and Production. https://doi.org/10. 1007/ s11250-020-02306-6.

DeJarnette, J.M., Leach, M.A., Nebel, R.L., Marshall, C.E., McCleary, C.R., Moreno, J.F. (2011). Effects of sex- sorting and sperm dosage on conception rates of Holstein heifers: Is comparable fertility of sex-sorted and conventional semen plausible? Journal Dairy Science. 94: 3477-3483.

DeJarnette, J.M., McCleary, C.R., Leach, M.A., Moreno, J.F., Nebel, R.L., Marshall, C.E. (2010). Effects of 2.1 and $3.5 \times 106$ Sex-Sorted Sperm Dosages on Conception Rates of Holstein Cows and Heifers. Journal of Dairy Science. 93(9): 4079-4085.

Dhami, A.J., Nakrani, B.B., Hadiya, K.K., Patel, J.A., Shah, R.G. (2015). Comparative efficacy of different estrus synchronization protocols on estrus induction response, fertility and plasma progesterone and biochemical profile in crossbred anestrus cows. Veterinary World. 8: 7-13.

Djedovic, R., Bogdanoviæ, V., Stanojeviæ, D., Nemes, Z., Gáspárdy, A., Cseh, S. (2016). Involuntary reduction in vigour of calves born from sexed semen. Acta Veterinaria Hungarica. 6(2): 229-238.
Doyle, S.P., Seidel, G.E., Schenk, J.L., Harrickhoff, L.A., Cran, D.G., Green, R.D. (1999). Artificial insemination of lactating Angus cows with sexed semen. Proceedings Western Section, American Society of Animal Science, Provo, Utah. 203-205.

Gaviraghi, A., Puglisi, R., Balduzzi, D., Severgnini, A., Bornaghi, V., Bongioni, G., Frana, A., Gandini, L.M., Lukaj, A., Bonacina, C., Galli, A. (2013). Minimum number of spermatozoa per dose in Mediterranean Italian buffalo (Bubalus bubalis) using sexed frozen semen and conventional artificial insemination. Theriogenology. 79: 1171-1176.

Healy, J. House, K. and Thomson, P.C. (2013). Artificial insemination field data on the use of sexed and conventional semen in nulliparous Holstein Heifers. Journal Dairy Sci. 96: 1905-1914.

Joshi, Sachin, Bhave, Kaustubh., Potdar, Vinod., Gaundare, Yuvraj., Punde, Nikhil., Shirsath. Tejashree., Swaminathan, Marimuthu (2021). Performance of sex sorted semen under Indian small holder dairy farming systems. Int. J. Curr. Microbiol. Appl. Sci. 10(02): 1335-1343.

Karakaya, E., Mecitoglu, G.Y., Keskin, A., Alkan, U., Gumen, A. (2014). Fertility in dairy cows after artificial insemination using sex-sorted sperm or conventional semen. Reproduction in Domestic Animal. 49: 333-337.

Kundalkar, A.D., Ingawale, M.V., Pawshe, M.D., Talokar, S.S., Pawshe, C.H., Deshmukh, S.G. (2014). Efficacy of Ovsynch and CIDR oestrus synchronization protocols in anoestrus buffaloes. Proc. XXIX Annual Convention of ISSAR and National Symposium held at Nagpur, India. P-142.

Kurykin, J., Hallap, T., Jalakas, M., Padrik, P., Kaart, T., Johannisson, A., Jaakmal U. (2016). Effect of insemination-related factors on pregnancy rate using sexed semen in Holstein heifers. Czech J. Anim. Sci. 61(12): 568-577.

Lu, Y., Liao, Y., Zhang, M., Yang, B., Liang, X., Yang, X., Lu, S., Wu, Z., Liang Y., Lu, K. (2015). A field study on artificial insemination of swamp and crossbred buffaloes with sexed semen from river buffaloes. Theriogenology. 84 : 862-870.

Lu, Y., Zhanga, M., Lua, S., Xub, D., Huangb,W., Menga, B., Xua, H., Lua, K. (2010). Sex-preselected buffalo (Bubalus bubalis) calves derived from artificial insemination with sexed sperm. Animal Reproduction Science. 119: 169-171.

Mallory, D.A., Lock, S.L., Woods, D.C., Poock, S.E., Patterson, D.J. (2013). Comparison of sex-sorted and conventional semen within a fixed-time artificial insemination protocol designed for dairy heifers. J. Dairy Sci. 96: 854-856.

Neglia, G.B., Gasparrini, R.D., Palo, C.D., Rosa, L., Campanile, C. (2003). Comparison of pregnancy rates with two estrus synchronization protocols in Italian Mediterranean buffalo cows. Theriogenology. 60: 125-133.

Norman, H.D., Hutchison, J.L., Mille, R.H. (2010). Use of sexed semen and its effect on conception rate, calf sex, dystocia and stillbirth of Holsteins in the United States. Journal of Dairy Science. 93: 3880-3890.

Parkavi, S., Ganesh, P., Kokila, M. (2021). All about panchagavya for human usage- A Review. Indian Journal of Natural Sciences. 1(64): 29173-29181. 
Patel, S.B. and Jethva P.C. (2019). Use of Sexed Semen in Indian Dairy Cattle: A Case Study Amul Research and Development Association (ARDA) Amul Dairy, Anand, Gujarat. The Indian Journal of Veterinary Sciences and Biotechnology. 14: $54-57$.

Paul, V. and Prakash, B.S. (2005). Efficacy of the Ovsynch protocol for Synchronization of ovulation and fixed-time artificila inseminationin Murrah buffaloes (Bubalus bubalis). Theriogenology. 64: 1049-1060.

Presicce, G.A., Verberckmoes, S., Senatore, E., Klinc, M.P., Rath, D. (2005). First established pregnancies in Mediterranean Italian Buffaloes (Bubalus bubalis) following deposition of sexed spermatozoa near the utero tubal junction. Reproduction in Domestic Animal. 40: 73-75.

Rhinehart, J.D., Arnett, A.M. anderson, L.H., Whittier, W.D., Larson, J.E., Burris, W.R., Elmore, J.B., Dean, D.T., DeJarnette, J.M. (2011). Conception rates of sex-sorted semen in beef heifers and cows. J. Anim. Sci. 89(2): 30-33.
Sewalem, A., Miglior, F., Kistemaker, G.J., Sullivan, P., Van Doormaal, B.J. (2008). Relationship between reproduction traits and functional longevity in Canadian dairy cattle. J. Dairy Sci. 91: 1660-1668.

Sharma, N., Chand, D.K., Rawat, S., Sharma, M., Verma, H. (2018). Effect of sexed semen on conception rate and sex ratio under field conditions. Journal of Entomology and Zoology. 6(1): 702-705.

Singh, S. (2014). Fertility response following fixed time insemination using Ovsynch based protocol in postpartum buffaloes M.V.Sc. Thesis NDVSU, Jabalpur (MP).

Stevenson, J.S., Kobayashi, Y., Shipka M.P., Ruchholz, K.C. (1996). Altering conception of dairy cattle by gonadotrophin releasing hormone preceding luteolysis induced by prostaglandin F2a. J. Dairy Sci. 79: 402-410.

Weigal, K.A. (2004). Exploring the role of sexed semen in dairy production systems. J. Dairy Sci. 87: (E. Suppl.): E120E130. 